\title{
Technical note: Manipulating interactions between plant stress responses and soil methane oxidation rates
}

\author{
Xiaoqi Zhou ${ }^{1,2,3}$, Cheng-Yuan $\mathrm{Xu}^{2,4}$, Shahla H. Bai ${ }^{2,5}$, Zhihong Xu ${ }^{2}$, Simeon J. Smaill ${ }^{6}$, Peter W. Clinton ${ }^{6}$, and \\ Chengrong Chen 2,3 \\ ${ }^{1}$ Tiantong National Station for Forest Ecosystem Research, Center for Global Change and Ecological Forecasting, Shanghai \\ Key Lab for Urban Ecological Processes and Eco-restoration, Institute of Eco-Chongming, School of Ecological and \\ Environmental Sciences, East China Normal University, Shanghai 200241, China \\ ${ }^{2}$ Environmental Futures Research Institute, Griffith University, Nathan, Brisbane, 4111, Australia \\ ${ }^{3}$ Griffith School of Environment, Griffith University, Nathan, Brisbane, 4111, Australia \\ ${ }^{4}$ School of Medical and Applied Sciences, Central Queensland University, Bundaberg, QLD, 4760, Australia \\ ${ }^{5}$ Faculty of Science, Health, Education and Engineering, University of the Sunshine Coast, \\ Maroochydore, DC QLD 4558, Australia \\ ${ }^{6}$ Scion, P.O. Box 29237, Riccarton, Christchurch 8440, New Zealand
}

Correspondence: Simeon J. Smaill (simeon.smaill@scionresearch.com)

Received: 23 February 2018 - Discussion started: 5 April 2018

Revised: 19 June 2018 - Accepted: 20 June 2018 - Published: 6 July 2018

\begin{abstract}
It has recently been hypothesised that ethylene, released into soil by stressed plants, reduces the oxidation of methane by methanotroph. To test this, a field trial was established in which maize plants were grown with and without soil moisture stress, and the effects of addition aminoethoxyvinylglycine (AVG; an ethylene biosynthesis inhibitor) and biochar (increases soil water holding capacity and reduces plant stress) were determined following the static incubation of soil samples. AVG increased methane oxidation rates by $50 \%(P=0.039)$, but only in the absence of irrigation. No other treatment effects were observed. This result provides evidence for a positive feedback system between plant stress, ethylene production, and impacts on methanotrophic activity.
\end{abstract}

\section{Introduction}

The atmospheric concentration of methane $\left(\mathrm{CH}_{4}\right)$ has almost tripled over the past 150 years, making a substantial contribution to climate change (Forster et al., 2007). Aerobic soils provide an important habitat for methanotrophic bacteria and the only significant biological sink for atmospheric $\mathrm{CH}_{4}$ (20-45 $\mathrm{Tg} \mathrm{CH}_{4} \mathrm{yr}^{-1}$ ) (Forster et al., 2007). However,
$\mathrm{CH}_{4}$ uptake by these soil ecosystems can be impacted by environmental stress (Kolb, 2009). A common plant physiological response to ecological stress, such as drought, is the production of ethylene (Morgan and Drew, 1997). In soils, however, ethylene may be inhibitory to methanotrophic activity (Jäckel et al., 2004; Pierek et al., 2006; Zhou et al., 2013) and thereby reduce $\mathrm{CH}_{4}$ oxidation. This potential interaction needs to be understood, as it may constitute an important positive feedback loop between climate disruption, soil ecosystem disturbance, and reduced $\mathrm{CH}_{4}$ removal from the atmosphere (Bousquet et al., 2006; Zhou et al., 2013).

To test our previous hypothesis that drought-induced in planta ethylene production reduces soil $\mathrm{CH}_{4}$ oxidation rates (Zhou et al., 2013), we manipulated plant stress responses by adding the ethylene biosynthesis inhibitor aminoethoxyvinylglycine ([S]-trans-2-amino-4(2-aminoethoxy)-3-butenoic acid hydrochloride; hereafter AVG) (Boller et al., 1979). In addition, the study tested the hypothesis that addition of biochar (BC) to soils may result in increased water holding capacity, reducing drought stress and thereby acting as a potential tool to maintain $\mathrm{CH}_{4}$ oxidation (Karhu et al., 2011). This is illustrated conceptually in Fig. 1, in which the application of irrigation (IR) and $\mathrm{BC}$ are able to maintain rates of $\mathrm{CH}_{4}$ oxidation by 


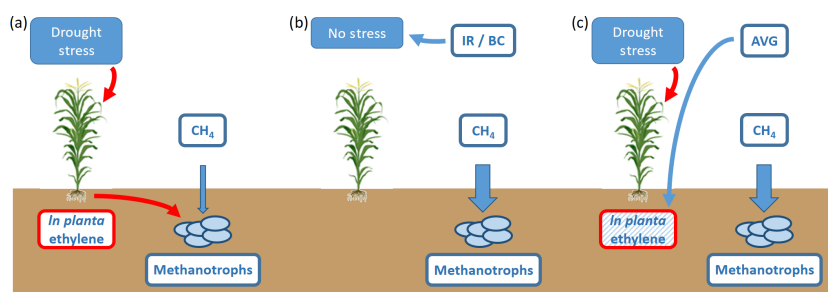

Figure 1. Conceptual outline of the proposed relationships between soil $\mathrm{CH}_{4}$ oxidation rates and aboveground plant biomass with regard to the anticipated effects of the treatments applied in this study. (a) Under environmental stress, in planta ethylene production is stimulated, resulting in ethylene exudation into the soil atmosphere and the inhibition of soil $\mathrm{CH}_{4}$ oxidation by methanotrophs. (b) The application of irrigation (IR) increases soil moisture while the application of biochar (BC) increases soil moisture holding capacity, both acting to reduce plant stress and prevent ethylene exudation into the soil atmosphere. (c) The application of AVG disrupts ethylene production, thus limiting or preventing the inhibition of $\mathrm{CH}_{4}$ oxidation by the stressed plant.

reducing moisture stress and therefore ethylene production, whereas AVG prevents the production of ethylene after the plant experiences stress.

\section{Material and methods}

\subsection{Study site}

The study site was located in the Bjelke-Petersen Research Station at Kingaroy $\left(26.53^{\circ} \mathrm{S}, 151.83^{\circ} \mathrm{E}\right)$ in the South Burnett Region of Queensland, Australia. Precipitation averages $789 \mathrm{~mm}$ per annum with erratic summer droughts frequent in the region. Soil at the field trial site soil is an acidic Red Ferrosol (pH 5.5) with high cation exchange capacity (Isbell, 1993). The site has a long history of cultivation, supporting peanut and maize rotations with winter fallows.

\subsection{Experiment design and management}

A full factorial, split-plot design field trial was established as follows: two IR treatments (IR and no IR) $\times$ two BC treatments $\left(\mathrm{BC}\right.$ at $9.2 \mathrm{tha}^{-1}$ and no $\left.\mathrm{BC}\right) \times$ two ethylene suppression treatments (AVG and no AVG). Each treatment had five replicates, producing a total of 40 plots. Due to practical concerns regarding application and maintenance, the IR treatments were established in two discrete areas that were spanned by five blocks. A schematic of the trial site is given in the Supplement (Fig. S1).

The $\mathrm{BC}$ treatment was established through application of peanut shell $\mathrm{BC}$ to the surface of the planting zone ( $\sim 450 \mathrm{~mm}$ wide strip each row) in early 2013 . The BC was incorporated into the soil with a rotary hoe to a depth of $200 \mathrm{~mm}$. The chemical properties of the peanut shell BC are provided in the Supplement (Table S1).
The site was machine planted with maize cultivar Pioneer 32p55 (Dupont Pioneer Australia) at a density of approximately 4 plants $\mathrm{m}^{-2}$ in late January 2014. Compound fertiliser $\left(\mathrm{N}: \mathrm{P}_{2} \mathrm{O}_{5}: \mathrm{K}_{2} \mathrm{O} 11.9: 14.1: 9.9\right)$ at $180 \mathrm{~kg} \mathrm{ha}^{-1}$ and urea at $100 \mathrm{~kg} \mathrm{ha}^{-1}$ were applied at sowing. Trickle tapes, installed into plots receiving IR, were used to distribute water equivalent to $\sim 50 \mathrm{~mm}$ of rainfall whenever there was a continuous dry spell for 2 weeks throughout the growing season (late January to late June).

To reduce the in planta production of ethylene, the commercial plant growth regulator ReTain (containing 15\% AVG; Valent Bioscience Cooperation, Walnut Creek, CA, USA) was sprayed onto the crop four times from mid-April to mid-June (the peak maize growth window) at intervals of 3 weeks. During each event, the treated rows of maize received approximately $750 \mathrm{~mL}$ of ReTain solution (prepared at the label rate of $1 \mathrm{~g}$ ReTain $1^{-1}$ water) directly to the surface of the plants.

\subsection{Sample collection and analysis}

In late June 2014, six soil cores from 0 to $100 \mathrm{~mm}$ depth were collected from the maize rooting zone of each plot using a $30 \mathrm{~mm}$ diameter soil auger. All samples were collected from the two middle rows of maize in each plot, and the six soil cores from within each plot bulked to a single plot sample. After sieving to $2 \mathrm{~mm}$, a $50 \mathrm{~g}$ (fresh mass) subsample of each sample was set aside for $\mathrm{CH}_{4}$ oxidation rate measurements and the remaining material dried at $105^{\circ} \mathrm{C}$ for $48 \mathrm{~h}$ to determine soil moisture content.

Soil $\mathrm{CH}_{4}$ oxidation rates were determined using the laboratory incubation. Briefly, about $20 \mathrm{~g}$ soil subsamples were incubated in $1 \mathrm{~L}$ glass jars at ambient atmospheric $\mathrm{CH}_{4}$ concentration (assumed to be $1.9 \mathrm{ppm}$ ) for 1 week in the dark at $25^{\circ} \mathrm{C}$. Headspace gas samples (approximately $30 \mathrm{~mL}$ ) were collected through a rubber septum in the jar lid at the beginning and the end of the incubation, and concentrations of $\mathrm{CH}_{4}$ were determined using GC-FID (GC-2010 Plus, Shimadzu, Japan). The $\mathrm{CH}_{4}$ oxidation rates in each jar were calculated from differences in the headspace $\mathrm{CH}_{4}$ concentration over the incubation time (Zhou et al., 2008) and adjusted to soil dry weight. Standards were measured once every 10 samples; the coefficient of variation in $\mathrm{CH}_{4}$ oxidation rate was less than $5 \%$ and control jars had ambient $\mathrm{CH}_{4}$ concentrations.

\subsection{Statistical analysis}

Statistical analysis was carried out in R 3.2.3 (Zhou et al., 2017) using a multi-factor ANOVA model incorporating an error structure accounting for the split-plot design associated with the non-random assignment of the IR treatment. The multi-comparison analysis methods provided in the "easyanova 4.0" $\mathrm{R}$ package was used to test for treatment interactions. 


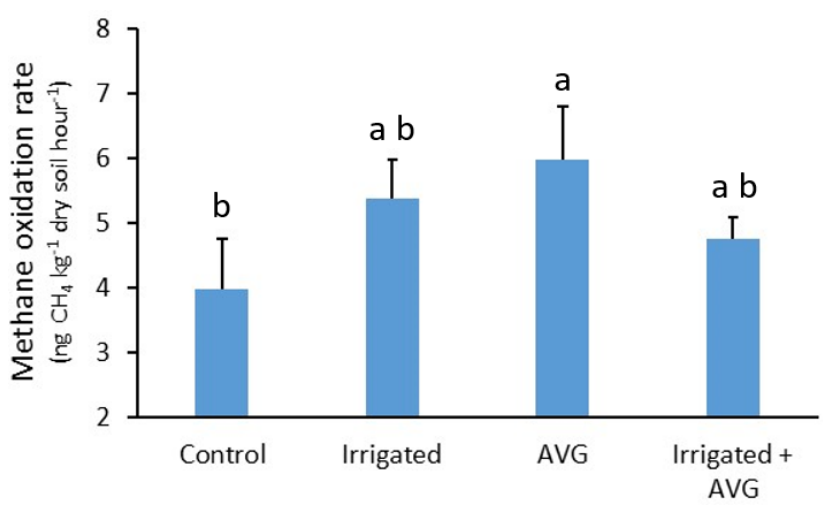

Figure 2. Response of soil $\mathrm{CH}_{4}$ oxidation rates to treatment with irrigation and AVG under maize plants. Letter groupings indicate significant differences at $P<0.05$; error bars are standard error of the mean. The biochar treatment did not influence results, so the data presented are the means of both biochar and no biochar treatments.

\section{Results}

Over the course of the field trial, five dry spells occurred. Irrigation to the IR plots resulted in delivery of $250 \mathrm{~mm}$ more water to this treatment than the controls. This resulted in significantly increased soil moisture $(P<0.001)$ in IR soils $(18.9 \%)$ compared with the non-irrigated soils $(15.4 \%)$ at sampling time. Neither the AVG nor BC treatments had any effect $(P>0.05)$ on soil moisture.

No significant main effects were observed, but a significant interaction between IR and AVG application was detected (Table 1). Exploration of this interaction with multicomparison analysis determined that $\mathrm{CH}_{4}$ oxidation rates were increased by $50 \%$ following AVG application $(P=$ 0.039), but only in the absence of IR (Fig. 2). The addition of $\mathrm{BC}$ had no effect on $\mathrm{CH}_{4}$ oxidation rates either as a main or interactive effect.

\section{Discussion}

The increase in $\mathrm{CH}_{4}$ oxidation with the AVG treatment either alone or in combination with the $\mathrm{BC}$ treatment aligns with past studies assessing the effect of increased ethylene concentrations on soil $\mathrm{CH}_{4}$ oxidation rates (Jäckel et al., 2004; $\mathrm{Xu}$ et al., 2008). This response also supports the hypothesis that in planta ethylene production in response to stress decreases the capacity of soil to support methanotrophic activity (Zhou et al., 2013).

The lack of effect of $\mathrm{BC}$ on $\mathrm{CH}_{4}$ oxidation is at odds with the results of previous work (e.g. Karhu et al., 2011; Kim et al., 2017). However, BC added in this study had no influence on soil moisture content, and this is proposed to be a key mechanism for $\mathrm{BC}$ to support $\mathrm{CH}_{4}$ oxidation in drought conditions (Karhu et al., 2011). Another reason for this might be related to the properties of the biochar $(\mathrm{C}: \mathrm{N}$ ratio of 51.84, $9.2 \mathrm{tha}^{-1}$ ) used in this study when compared with agricultural soils in Finland $\left(\mathrm{C}: \mathrm{N}\right.$ ratio of $\left.101.07,9 \mathrm{tha}^{-1}\right)$ (e.g. Karhu et al., 2011) and in East Asia (C:N ratio of 79.65, $2 \mathrm{tha}^{-1}$ ) (e.g. Kim et al., 2017). The lower $\mathrm{C}: \mathrm{N}$ ratio of the biochar used in this study can incorporate more $\mathrm{N}$ fertiliser into the soils, which could reduce soil $\mathrm{CH}_{4}$ uptake as $\mathrm{N}$ fertiliser can inhibit methanotrophic activities (see Kolb, 2009). Overall, the reason why BC addition did not result in increased soil moisture in this case is unclear. Further studies is needed to investigate the effects of biochar application on the factors influencing soil $\mathrm{CH}_{4}$ oxidation.

The significant interaction between the AVG and IR treatments is more difficult to reconcile. The IR treatment was intended to significantly increase soil moisture content compared to the no IR treatment, reducing water stress and likely in planta ethylene production. It was noted that increased soil moisture content can directly influence methanotrophic activity, as water-driven increases in microbial activity can enhance methanotroph, whereas water content that exceed field capacity can rapidly decrease $\mathrm{CH}_{4}$ oxidation rates by reducing gas mobility through soil pores (Le Mer and Roger, 2001). Given the initial soil water content and scale of the increase with the IR treatment, direct stimulation of $\mathrm{CH}_{4}$ oxidation was considered the most likely outcome when considering plant-independent effects. Consequently, it was anticipated that any effect of AVG on $\mathrm{CH}_{4}$ oxidation (putatively via reductions in ethylene production) would only manifest without IR, as the IR treatment would make the AVG treatment redundant. However, $\mathrm{CH}_{4}$ oxidation rates in plots treated with either IR or IR and AVG in combination were not significantly greater than untreated control plots. It is possible that the moisture addition associated with the IR treatment was insufficient to substantially alleviate plant drought stress, driving an increase in ethylene production, which could then account for the numerical difference between the AVG and IR treatments (Fig. 2). The water addition may have also been insufficient to meaningfully and directly stimulate methanotroph activity. However, it would be expected that the combination of IR and AVG would support soil $\mathrm{CH}_{4}$ oxidation rates either the same or potentially greater than those observed for AVG alone. This was not the case, and the explanation for the significant interaction remains unknown. As discussed above, it is possible for increased soil moisture content to inhibit $\mathrm{CH}_{4}$ oxidation via decreased porosity and gas diffusion (see Zhou et al., 2014), but, given the IR treatment alone did not reduce $\mathrm{CH}_{4}$ oxidation rates relative to the control, this is not a feasible explanation in this case.

The lack of data explicitly describing ethylene release into soil in response to the treatments is a limitation to this trial. However, the quantification of ethylene in soil is not trivial, particularly when conducted over time (i.e. continuous), and was outside the resources available for this study. However, given the findings of this study, and considering treatments 
Table 1. Analysis of treatment effects on methane oxidation rates, accounting for the split-plot design of the trial.

\begin{tabular}{lrrrrr}
\hline Block & Degrees of freedom & Sum square & Mean square & $F$ value & Probability $(>F)$ \\
\hline Residuals & 4 & 25.27 & 6.318 & & \\
IR & 1 & 0.057 & 0.057 & 0.01 & 0.925 \\
Residuals & 4 & 22.785 & 5.696 & & \\
BC & 1 & 0.946 & 0.946 & 0.245 & 0.634 \\
IR: BC & 1 & 0.815 & 0.815 & 0.211 & 0.658 \\
Residuals & 8 & 30.924 & 3.865 & & \\
AVG & 1 & 4.77 & 4.768 & 1.796 & 0.199 \\
IR: AVG & 1 & 17.38 & 17.384 & 6.549 & 0.021 \\
BC: AVG & 1 & 6.19 & 6.186 & 2.33 & 0.146 \\
IR: BC:AVG & 1 & 0.42 & 0.422 & 0.159 & 0.695 \\
Residuals & 16 & 42.47 & 2.654 & & \\
\hline
\end{tabular}

were field-based, further investigations of the interactions between AVG, plant stress, and $\mathrm{CH}_{4}$ oxidation should be conducted. In these studies, consideration should be given to collection and integration of ethylene data, particularly given that these data may help shed light on the nature of any interactions between treatments.

Overall, the findings of this study indicate that application of an ethylene biosynthesis inhibitor to plant tissue can cause a measurable increase in the capability of soil to oxidise $\mathrm{CH}_{4}$ under moisture-stressed conditions. This supports the hypothesis that the stress-induced production of ethylene by plants can disrupt the activity of methanotrophs and identify a potential management pathway to help retain, or even enhance, the methanotrophic capability of soils in productive systems. Given the global importance of a positive feedback between environmental stress, plant ethylene production, and lowered microbial $\mathrm{CH}_{4}$ oxidation activity, further work in this area is needed. In addition, methods to moderate impacts on the methanotrophic community, such as use of alternative forms or rates of biochar application, require investigation to enable provision of important ecosystem services.

Data availability. The soil physicochemical properties and soil methane oxidation rate data are available upon request to the lead author.

Supplement. The supplement related to this article is available online at: https://doi.org/10.5194/bg-15-4125-2018-supplement.

Author contributions. PWC, SJS, and XZ conceived the idea; XZ and CYX designed the experiment; CYX and SHB performed soil methane oxidation measurements; $\mathrm{ZX}$ and $\mathrm{CC}$ contributed the materials and agents; and $\mathrm{XZ}$ and SJS analyzed these data and drafted the manuscript.
Competing interests. The authors declare that they have no conflict of interest.

Acknowledgements. The research was jointly supported by National Natural Science Foundation of China (no. 31600406), Shanghai Science and Technology Innovation Fund (no. 18391902300), Griffith University Research Fellowship, a Collaborative Research Network of the University of the Sunshine Coast Research Futures Project Seed Grant, New Zealand, and the "Growing Confidence in Forestry's Future" research programme (C04X1306), which is jointly funded by the Ministry of Business Information and Employment (MBIE) and the Forest Growers Levy Trust, with the support of the NZ Forest Owners Association (FOA) and the NZ Farm Forestry Association (FFA).

Edited by: Jianming Xu

Reviewed by: two anonymous referees

\section{References}

Argueso, C. T., Hansen, M., and Kieber, J. J.: Regulation of ethylene biosynthesis, J. Plant. Growth. Regul., 26, 92-105, 2007.

Boller, T., Herner, R. C., and Kende, H.: Assay for and enzymatic formation of an ethylene precursor, 1-aminocyclopropane1-carboxylic acid, Planta, 145, 293-303, 1979.

Bousquet, P., Ciais, P., Miller, J. B., Dlugokencky, E. J., Hauglustaine, D. A., Prigent, C., van der Werf, G. R., Peylin, P., Brunke E. G., Carouge, C., Langenfelds, R. L., Lathière, J., Papa, F., Ramonet, M., Schmidt, M., Steele, L. P., Tyler, S. C., and White, J.: Contribution of anthropogenic and natural sources to atmospheric methane variability, Nature, 443, 439-443, 2006.

Forster, P., Ramaswamy, V., Artaxo, P., Berntsen, T., Betts, R., Fahey, D. W., Haywood, J., Lean, J., Lowe, D. C., Myhre, G., Nganga, J., Prinn, R., Raga, G., Schulz, M., and van Dorland, R.: Changes in atmospheric constituents and in radiative forcing,edited by: Solomon, S., Qin, D., Manning, M., Alley, R., Berntsen, T., Bindoff, N., Chen, Z., Chidthaisong, A., Gregory, J., Hegerl, G., Heimann, M., Hewitson, B., Hoskins, B., Joos, F., Jouzel, J., Kattsov, V., Lohmann, U., Matsuno, T., Molina, M., Nicholls, N., Overpeck, J., Raga, G., Ramaswamy, V., Ren, J., 
Rusticucci, M., Somerville, R., Stocker, T., Whetton, P., Wood, R., and Wratt, D., Climate Change 2007: The Physical Science Basis, Cambridge University Press, UK, 130-234, 2007.

Ho, A., Reim, A., Kim, S. Y., Meima-Franke, M., Termorshuizen, A., de Boer, W., van der Putten, W. H., and Bodelier, P. L. E.: Unexpected stimulation of soil methane uptake as emergent property of agricultural soils following bio-based residue application, Glob. Change Biol., 21, 3864-3879, 2015.

Isbell, R. F.: A classification system for Australian soils (third approximation) CSIRO Australia Division of Soils Technical Report 2/1993, CSIRO Division of Soils and National Landcare Program project, Townsville, 1993.

Jäckel, U., Schnell, S., and Conrad, R.: Microbial ethylene production and inhibition of methanotrophic activity in a deciduous forest soil, Soil Biol. Biochem., 36, 835-840, 2004.

Karhu, K., Mattila, T., Bergström, I., and Regina, K.: Biochar addition to agricultural soil increased $\mathrm{CH}_{4}$ uptake and water holding capacity - Rresults from a short-term pilot field study, Agric. Ecosyst. Environ., 140, 309-313, 2011.

Kim, J., Yoo, G., Kim, D., Ding, W., and Kang, H.: Combined application of biochar and slow-release fertilizer reduces methane emission but enhances rice yield by different mechanisms, Appl. Soil Ecol., 117-118, 57-62, 2017.

Kolb, S.: The quest for atmospheric methane oxidizers in forest soils, Environ. Microbiol Rep., 1, 336-346, 2009.
Le Mer, J. and Roger, P.: Production, oxidation, emission and consumption of methane by soils: A review, Eur. J. Soil Biol., 37, 25-50, 2001.

Morgan, P. W. and Drew, M. C.: Ethylene and plant responses to stress, Physiologia Plantarum, 100, 620-630, 1997.

Pierik, R., Tholen, D., Poorter, H., Visser, E. J. W., Voesenek, L. A. C. J.: The Janus face of ethylene: growth inhibition and stimulation, Trends Plant Sci., 11, 176-183, 2006.

$\mathrm{Xu}, \mathrm{X} .$, Yuan, B., and Wei, J.: Vertical distribution and interaction of ethylene and methane in temperate volcanic forest soils, Geoderma, 145, 231-237, 2008.

Zhou, X. Q., Wang, Y. F., Huang, X. Z., Tian, J. Q., and Hao, Y. B.: Effect of grazing intensities on the activity and community structure of methane-oxidizing bacteria of grassland soil in Inner Mongolia, Nutr. Cycl. Agroecosys, 80, 145-152, 2008.

Zhou, X. Q., Smaill, S. J., and Clinton, P. W.: Methane oxidation needs less stressed plants, Trends Plant. Sci., 18, 657-659, 2013.

Zhou, X. Q., Dong, H. B., Chen, C. R., Smaill, S. J., and Clinton, P. W.: Ethylene rather than dissolved organic carbon controls methane uptake in upland soils, Glob. Change Biol., 20, 23792380, 2014.

Zhou, X., Guo, Z., Chen, C., and Jia, Z.: Soil microbial community structure and diversity are largely influenced by soil $\mathrm{pH}$ and nutrient quality in 78-year-old tree plantations, Biogeosciences, 14, 2101-2111, https://doi.org/10.5194/bg-14-2101-2017, 2017. 